\title{
SOCIETY OPPOSES WINTEGO DAM
}

At its Annual Meeting on October 15, 1977, the Saskatchewan Natural History Society passed a resolution urging the Government of Saskatchewan to abandon plans to build the Wintego Dam. The resolution also asked the Churchill River Board of Inquiry to recommend "alternative uses for the area compatible with needs of the local people and the protection of the environment."

In supporting the resolution, the Society emphasized the uniqueness of the Churchill as a white-water wilderness river, and maintained that the social, cultural and environmental costs of building a dam on the Churchill far outweigh any economic or energy benefits that might be derived from it.

A brief to support the Society's stand was presented to the Churchill River Board of Inquiry at hearings in Saskatoon on November 26, 1977. It was argued by Dr. Stuart Houston, who presented the Society's brief, that the public at large supports the Society's stand, although everyone recognizes the complexity of the question. The Society, like the general public, is concerned about the natural environment and about the native people who have made this area their home for generations.

"As naturalists," Dr. Houston said, "we have studied carefully the Churchill River Study Technical Report. We share the concerns in this report about the effect a dam at Wintego would have on water quality and aquatic life, including changes in depth, temperature, nutrients, chemistry and sedimentation, but wish to emphasize particularly the loss of purifying aeration at present rapids. The many effects on fish, plants, mammals, adjacent wetlands and forests have been noted by us with some apprehension."

To make the point about effects of the dam on wildlife, a striking example was cited - that of the endangered Bald Eagle. The Bald Eagle has virtually disappeared as a nesting species from the eastern half of North America and, although it still thrives along the ocean coasts of British Columbia and Alaska, its greatest inland stronghold is northern Saskatchewan. Its very best habitat includes the Churchill River and its tributaries, with one pair for every 9 to 28 shoreline miles, a heavy density for such a large bird.

"Bald Eagles need rapids," the brief said, "almost half the nests in the Churchill River Study area were within half a mile of rapids. A dam at Wintego would submerge many rapids where the eagles get much of their food, especially when they first return ... at the end of March. If there are no rapids, the large lake above the dam will not open until perhaps the end of May, and the eagles will either start nesting before there is a reliable food supply, or their nesting will be delayed beyond the optimum timetable of nature, with equally disastrous results.

"An even greater threat to the eagles is the influx of a thousand or so workers involved in building a dam. Human pressure has had adverse effects on eagle breeding success everywhere in settled North America. In addition, there is for some as yet unexplained reason a drastic decrease in the number of breeding pairs for an appreciable number of miles both above and below a dam; this is obvious from a plotting of eagle nest locations on either side of the Island Falls dam in the Technical Survey data." 


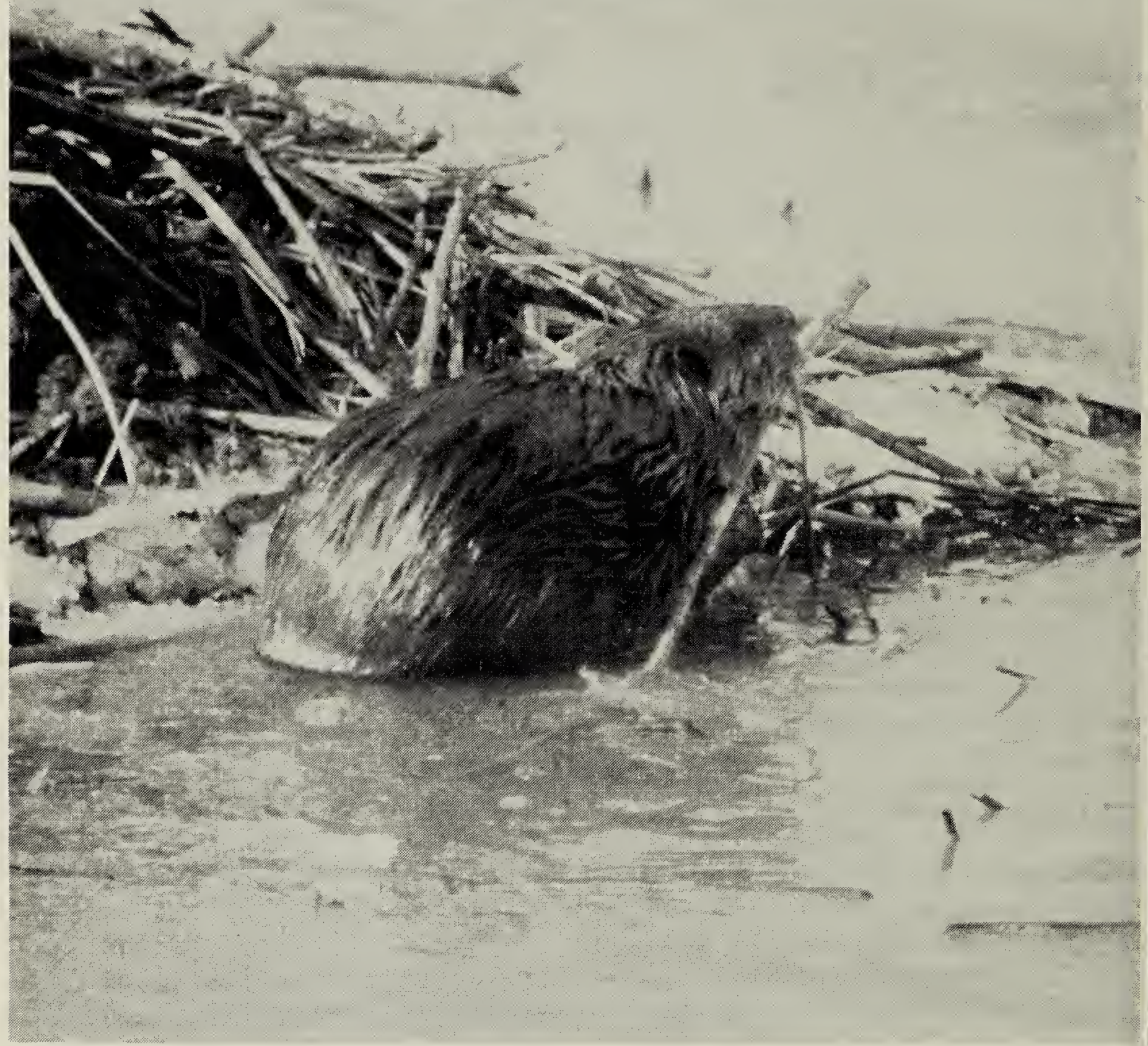

Technology, Dr. Houston reminds us, can destroy - but not create, the Eagle.

In the Society's view, the harm done by the reversal of natural processes by hydro engineers, though recognized in the Technical Report in the case of two fur-bearing animals, the beaver and the muskrat, is not sufficiently emphasized, and many other species have not been adequately studied. Once a dam is built water flows are artificially controlled, to be released over the dam in winter when electricity needs are greatest and stored in summer when energy needs are lowest - the opposite of the natural scheme of things.

Most important, however, are the effects on the native people in the north. For nearly 300 years the Churchill has been their major highway. The historic aspect alone would justify preservation of the river. But the Churchill is still a water highway, used extensively by the native people, and also by an increasing number of white-water canoeists, to whom it offers some of the finest white-water canoeing and wilderness experience in the world. In the winter, the river is still a highway because the ice forms a solid path for snowshoes, dogteams, 
motorized toboggans and bombadiers, and the river can be safely crossed except at the rapids.

The Wintego dam, on the other hand, would create a large, two-armed lake no longer safe except for large expensive boats with energy-guzzling motors. In winter, drawdowns would make the ice unsafe to cross at any time.

A Wintego dam would destroy the wilderness recreation and white-water canoeing that now exists. Add to the dam the destruction caused by building long power transmission lines, the impact of which the Technical Report did not adequately assess.

Furthermore, the Wintego dam might be only the first of a series. The Society has "watched with alarm how, once a dam is constructed on a river system the engineers present arguments for 'maximizing the potential and gaining more control by building a series of dams on the one system" (as on the Winnipeg and Nelson rivers in Manitoba).

"If one MUST build a series of dams on a river system, the Saskatchewan Natural History Society would reluctantly prefer the Saskatchewan River system, where two dams already exist; where the livelihood of only a few valley-bottom farmers would be affected and where appropriate compensation would be feasible, rather than wholesale disturbance of an entire culture and life-style; where a lake formed would be close to those desiring a lake; where relatively few lakes exist and where less energy is expended getting there; where water recreation would be increased, not destroyed; where transportation of nearby residents and crossing of the river would not be seriously affected; where the power produced would be near the people wishing it; where the transmission lines would avoid defacing sensitive northern terrain; where the historic, pictographic and aesthetic aspects are less important; where the destruction of unique wilderness and white-water canoeing is not at stake; and, finally, where the survival of a threatened species, the national emblem of our immediate neighbor, is not involved."

But naturalists recoil at the culture shock that such developments create for the native people in the north. They disagree with the philosophy and conclusions of the cost-benefit analysis of the Technical Report, and consider it particularly inappropriate to attempt to measure in dollars the value of the traditional way of life of a people who lived successfully on the land for thousands of years before the white man came. Similarly, it is impossible to place a dollar value on Nature.

Finally, it is the view of the Society that man must take a new attitude toward his needs, abandoning the popular growth-for-growth's-sake ethic. If we accept the need for continuing increases in electrical consumption, based on SPC forecasts for the future, by the early part of the next century we will need a new dam every month! These SPC forecasts are to a large extent self-fulfilling, for use will rise to meet production. The Society has been critical of material supplied to the Inquiry by the SPC because none of it comes to grips with viable alternatives. In the opinion of the Saskatchewan Natural History Society, the worst possible policy would be to accept, encourage tacitly, and plan for, ever-increasing use of electricity.

It is misleading to talk glibly of hydro power as a renewable resource. While the water itself is renewable, a dam at Wintego would DESTROY a major portion of the Churchill River, along with its environment and wildlife, which are not renewable. 